\title{
Context specificity of sensory preconditioning: Implications for processes of within-event learning
}

\author{
JASPER WARD-ROBINSON, MICHELLE SYMONDS, and GEOFFREY HALL \\ University of York, York, England
}

\begin{abstract}
A variant of the taste aversion procedure for sensory preconditioning, as used by Rescorla and Cunningham (1978), was employed in a study of the context dependency of within-event learning. In two experiments, rats received Phase 1 exposure to a simultaneous flavor compound, AX; flavor X was paired with illness during Phase 2 , and any tendency for the resulting aversion to be elicited by A was measured. It was found that subjects were less likely to shun flavor A as a consequence of this training if the Phase 1 and test episodes were conducted in distinctively different contexts. This effect was evident both when the change of context occurred just before the test with flavor A (Experiment 1) and when it occurred before Phase 2 (Experiment 2). These results were taken to imply that, as is often found with serial associations, the retrieval of within-event associations is subject to contextual control. The implications of these findings for the interpretation of perceptual learning effects are discussed.
\end{abstract}

A conditioned response (CR) established by Pavlovian conditioning in one context will often fail to appear in full strength when the conditioned stimulus (CS) is presented in a different context. For example, Hall and Honey (1989) gave rats training in which a CS was paired with the unconditioned stimulus (US) of food in an apparatus having distinctive visual and olfactory features; responding to the CS was found to be greater in this training apparatus than in a second apparatus characterized by different olfactory and visual cues. The interpretation offered by Hall and Honey (1989) was that the contextual cues had acquired the ability to facilitate the retrieval of associative information acquired in their presence; a change of context thus made retrieval less efficient and restricted the ability of the CS to evoke the CR.

Although in some circumstances conditioned responding appears to be insensitive to a context change (e.g., Bouton \& King, 1983; Bouton \& Peck, 1989; Kaye \& Mackintosh, 1990; Lovibond, Preston. \& Mackintosh. 1984), the effect has been successfully demonstrated for a range of training procedures. It has been shown not only for rats and appetitive conditioning (e.g. Good \& Honey, 1991; Hall \& Honey, 1989), but also in pigeon autoshaping (Honey, Willis, \& Hall, 1990), in flavor aversion learning (Bonardi, Honey, \& Hall, 1990), and for some instances of the conditioned emotional response (e.g., Hall \& Honey, 1990; Swartzentruber \& Bouton, 1992). In all these procedures. training involves sequential presenta-

This work was supported by grants from the U.K. Biotechnology and Biological Sciences and Medical Research Councils. We thank Charlotte Bonardi and David Purves for helpful diseussion. Correspondence concerning this article should be addressed to J. Ward-Robinson. Department of Psychology, University of York. York YOI 5DD. England (e-mail: jwrl (a york.ac.uk). tion of events, with the CS signaling the occurrence of the US. There is no reason, however, to suppose that contextual control will be restricted to this form of learning; the question addressed by the experiments reported here was whether such control can be seen in the case of the within-compound learning produced by the simultaneous presentation of stimuli. To this end, we made use of a sensory preconditioning procedure.

In sensory preconditioning (e.g., Brogden, 1939), subjects first receive pairings of two neutral stimuli; in a second phase, the value of one of these stimuli is modified by pairing it with a US. A final test demonstrates that the stimulus not trained in Phase 2 is also capable of evoking the CR. In some examples of sensory preconditioning, the procedure used in Phase 1 follows that used in orthodox classical conditioning, with one of the stimuli preceding the occurrence of the other. But sensory preconditioning can be obtained with Phase 1 training in which the target events are presented as a simultaneous compound. Thus, for example, preexposure to a compound stimulus consisting of a mixture of two flavors will allow an aversion subsequently conditioned to one of the elements to be elicited by the other (Rescorla \& Cunningham, 1978; Rescorla \& Freberg, 1978). We adopted this procedure in the experiments to be described in this paper.

We were interested in examining the context specificity of this form of sensory preconditioning for two chief reasons. First, as we have already pointed out, most demonstrations of the context specificity of conditioning have examined the effect after training in which the CS has predicted the occurrence of the US. This sensory preconditioning procedure allows convenient study of the learning that goes on during the simultaneous pairing of stimuli, learning that has sometimes been supposed to depend on principles different from those that govern the associations 
Table 1

Summary of the Experimental Designs

\begin{tabular}{|c|c|c|c|}
\hline \multirow[b]{2}{*}{ Context } & \multicolumn{2}{|c|}{ Phase } & \multirow[b]{2}{*}{ Test } \\
\hline & 1 & 2 & \\
\hline \multicolumn{4}{|c|}{ Experiment 1} \\
\hline 1 & $\mathrm{AX} \& \mathrm{BY}$ & $X+\& Y-$ & $\begin{array}{c}\text { A vs. B } \\
\text { (in Context } 1 \text { for Group S) }\end{array}$ \\
\hline 2 & W & W & $\begin{array}{c}\text { A vs. B } \\
\text { (in Context } 2 \text { for Group D) }\end{array}$ \\
\hline \multicolumn{4}{|c|}{ Experiment 2} \\
\hline 1 & $\mathrm{AX}$ & $\mathrm{X}+\mathrm{Y}+$ & A vs. B \\
\hline 2 & BY & & \\
\hline
\end{tabular}

Note- $A$ and $B$ refer to sucrose and saline solutions; $X$ and $Y$, to quinine and hydrochloric acid solutions; W, to water. Solutions were presented to rats as compound during Phase 1 (e.g., $\mathrm{AX}$ ) and as elements during Phase 2 and test. "+" refers to the reinforcement, and "-" to the nonreinforcement, of a solution by an intraperitoneal injection of $0.30 \mathrm{M}$ lithium chloride $(10 \mathrm{ml} / \mathrm{kg})$. During Phase 1 of Experiment 1 , all rats received $\mathrm{AX}$ and $\mathrm{BY}$ in Context 1 and $\mathrm{W}$ in Context 2 . After this, in Phase $2, \mathrm{X}$ and $\mathrm{Y}$ underwent discriminative conditioning in Context 1; again $\mathrm{W}$ was given in Context 2 . Finally, testing to $\mathrm{A}$ and $\mathrm{B}$ was given, but in different environments for different rats: for Group $\mathrm{S}$, testing was given in Context 1 , but for Group D, it occurred in Context 2. During Phase 1 of Experiment 2, all rats were presented with $\mathrm{AX}$ in Context 1 and $B Y$ in Context 2. Next, in Phase 2, rats were conditioned to $X$ and $\mathrm{Y}$ and tested to $\mathrm{A}$ and $\mathrm{B}$; these treatments occurred in Context 1 .

formed during the learning of predictive relationships (see, e.g., Rescorla, 1981; Rescorla \& Freberg, 1978). A demonstration that sensory preconditioning shows context specificity, as do some instances of more standard forms of associative learning, would therefore bolster attempts to analyze within-event learning in terms of orthodox associative principles. Second, if sensory preconditioning proved to be context specific, this would have implications for a range of other phenomena (in particular for latent inhibition and perceptual learning effects) produced by procedures in which subjects are given nonreinforced presentations of stimuli prior to conditioning. This issue will be taken up in the General Discussion.

\section{EXPERIMENT 1}

The design of Experiment 1 was modeled on that used by Rescorla and Cunningham (1978) and is summarized in the upper part of Table 1. There were two groups of subjects. Both were preexposed to two simultaneous compounds, AX and BY, the basic elements of which were the flavors salt, sweet, bitter, and acid. In the next phase of training, $\mathrm{X}$ and $\mathrm{Y}$ were presented individually; $\mathrm{X}$ was followed by a US (an injection of lithium chloride, $\mathrm{LiCl}$ ) whereas $Y$ was not. A final test compared the strength of the aversions governed by $A$ and $B$. A reduced consumption of flavor A relative to flavor B would indicate the occurrence of sensory preconditioning. This within-subjects measure of sensory preconditioning incorporates an important control - it allows us to conclude that any rejection of A on test depends specifically on its having been experienced along with a stimulus subsequently paired with the US rather than on some other, more general, effect of compound preexposure.

The associative account of sensory preconditioning assumes that an associative link is formed between $A$ and $\mathrm{X}$ during preexposure to the $\mathrm{AX}$ compound. By virtue of this link, when $A$ is presented in the test phase it will be able to activate a representation of $X$ which will have formed an association with the US during Phase 2. By this indirect route, A will be able to activate the US representation and thus evoke a CR. For subjects in Group $S$ (same), the Phase 1, Phase 2, and test episodes were conducted in the same context (Context 1). For those in Group D (different), the test with stimulus A took place in a different context (Context 2) from that in which Phases 1 and 2 had occurred. According to the associative interpretation of sensory preconditioning, if the effectiveness of the $\mathrm{A}-\mathrm{X}$ association depends on the presence of the original contextual cues, the magnitude of the sensory preconditioning effect will be attenuated by the change of context experienced by Group D.

\section{Method}

Subjects and Apparatus. The subjects were 16 male hooded Lister rats with a mean weight of $426 \mathrm{~g}$ (range: $390-470 \mathrm{~g}$ ). They had previously served as subjects in an experiment involving conditioning with a shock US and an instrumental, food-reinforced baseline, but they were naive with respect to the stimuli and procedures used in this experiment. The subjects were housed in pairs in their home cages, where they were permitted continuous access to food. Access to water was restricted as detailed below.

Two sets of cages, both different from the home cages, served as the experimental contexts. These were known to be discriminable from one another, being essentially the same as those used in previous studies of the role of contextual factors in flavor aversion conditioning (see Bonardi et al., 1990; Honey, Pye, Lightbown, Rey, \& Hall, 1992). One set consisted of large cages, $42 \times 35 \times 16 \mathrm{~cm}$, that were located in the brightly lit main colony room. The walls and floor of the cages were made of translucent white plastic and the wire mesh roof included a section through which a drinking spout could be inserted. The cages in the second set were smaller, measuring $35 \times 22 \times 19 \mathrm{~cm}$. They were located in a separate part of the laboratory, in a small room that was dimly lit by a $60-\mathrm{W}$ red light and that contained a speaker supplying a background of white noise with an intensity of $75 \mathrm{~dB}$ (scale A) measured at the position of the cages. The walls and floors of the smaller cages were composed of transparent plastic, and the roof was composed of wire mesh. The floor was covered with commercially obtained cat litter.

Measured amounts of tap water, $0.33 \mathrm{M}$ sucrose, $0.16 \mathrm{M}$ saline, $60.0 \mu \mathrm{M}$ quinine, and $0.01 \mathrm{M}$ hydrochloric acid were administered with inverted $50-\mathrm{ml}$ centrifuge tubes fitted with ball-bearing-tipped spouts. When the solutions were presented as compounds, they were made up so as to maintain the molarity of the individual flavors. A balance was used to record fluid consumption to the nearest $0.5 \mathrm{ml}$.

Procedure. A schedule of water deprivation was first established in the home cages. The standard water bottles were removed overnight and, on the next 2 days, access to fluid was restricted to twicedaily 30 -min presentations initiated at 1100 and $1700 \mathrm{~h}$. On the next day, the animals were moved to one or the other of the experimental contexts at each of these times, where they received access to water for $30 \mathrm{~min}$ before being returned to their home cages. Half the subjects were put in the large cages in their morning session and in the smaller cages in the afternoon; for the remainder, this arrangement was reversed. Except where noted, subjects continued to re- 


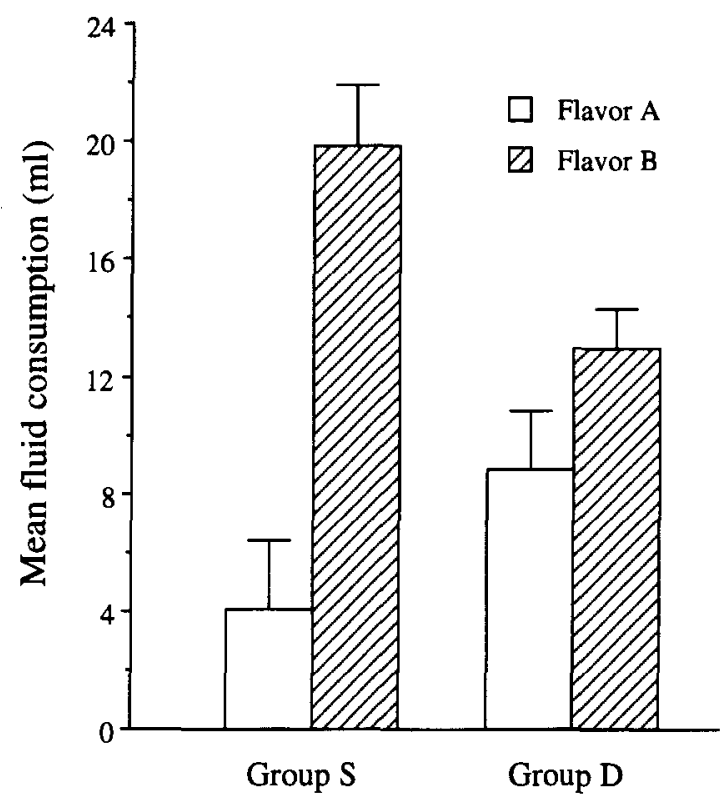

Figure 1. Experiment 1. Group mean consumption (in milliliters) of $A$ and $B$ per test session. A refers to the flavor that had been preexposed in compound with that used as the conditioned stimulus $(X)$. Stimulus $B$ had been preexposed in the presence of the nonreinforced $Y$ flavor. The group designation refers to whether the test phase took place in the same context as that used for preexposure and conditioning (Group $S$ ) or in a different context (Group D). Error bars indicate the standard error of the mean.

ceive two daily 30 -min sessions, one in each context, throughout the rest of the experiment.

During the first phase of training all subjects received, over 8 days, four 10-ml presentations of each of two compound flavors, $\mathrm{AX}$ and $\mathrm{BY}$, in Context 1 . The 8 subjects assigned to Group $\mathrm{S}$ experienced the flavored solutions in their morning contexts; the 8 subjects assigned to Group D were given the flavors in their afternoon contexts. Half of the subjects in each of these groups experienced the large cages in the morning and the small cages in the afternoon; the other animals experienced the reverse. During the daily session in the other experimental context, Context 2, $5 \mathrm{ml}$ of water was presented. For half of the subjects in each group, stimulus $\mathrm{X}$ was acid and stimulus $\mathrm{Y}$ was quinine, and for half, $\mathrm{Y}$ was quinine and $\mathrm{X}$ was acid. Half of the subjects in the subgroups so formed had sucrose as stimulus $\mathrm{A}$ and saline as stimulus $\mathrm{B}$; the remainder had the reverse arrangement. The compounds were presented on alternate days, beginning with $\mathrm{AX}$ for half the subjects and with $\mathrm{BY}$ for the others.

On the day following the end of Phase 1 , the animals received a conditioning trial which consisted of a $30-\mathrm{min}, 10-\mathrm{ml}$ presentation of flavor X followed by an intraperitoneal injection of $0.30 \mathrm{M} \mathrm{LiCl}$ at $10 \mathrm{ml} / \mathrm{kg}$ body weight. The injection was given just before the subjects were returned to their home cages. For all subjects, flavor $\mathrm{X}$ was presented in Context 1 , the context in which they had received exposure to the $\mathrm{AX}$ and $\mathrm{BY}$ compounds; as before, subjects continued to receive $5 \mathrm{ml}$ of water in Context 2 . The following day was a recovery day on which the animals were allowed free access to water in the home cage for two 30 -min sessions, at 1100 and $1700 \mathrm{~h}$. On the next day, all subjects received, in the context in which they had received conditioning with $\mathrm{X}$, a $30-\mathrm{min}, 10-\mathrm{ml}$ nonreinforced presentation of stimulus $\mathrm{Y}$. This was followed by a further recovery day. The entire 4-day cycle was then repeated so that the animals had two reinforced trials with $\mathrm{X}$ and two nonreinforced trials with $\mathrm{Y}$.
Following Phase 2, the subjects received a two-bottle test in which they were presented with free access to flavors A and B in their morning context. For the animals in Group $\mathrm{S}$, therefore, this was the same context as that in which Phases 1 and 2 had occurred (Context 1); for the animals in Group D, the test context was that in which only water had been presented (Context 2 ). For half the subjects in each group, the bottle containing flavor $A$ was presented on the left-hand side of the context cage, and the bottle containing flavor $\mathrm{B}$ was presented on the right; for the remainder, the arrangement was reversed. As before, all subjects received access to $5 \mathrm{ml}$ of water in their afternoon contexts. After a recovery day, the subjects were given a second test session, identical to the first.

\section{Results and Discussion}

Recall that during Phase 1 , Group S received flavors in the morning, whereas Group D received flavors in the afternoon. This confound appeared to be unimportant, in that during that phase of training, rats in both groups rarely failed to consume all of the $10 \mathrm{ml}$ of fluid that was offered.

The subjects came to show suppressed consumption of the $\mathrm{X}$ flavor on the training trials of Phase 2. For Group $\mathrm{S}$, the mean amount of fluid consumed fell from $9.7 \mathrm{ml}$ on the first trial to 4.4 on the second; corresponding data for Group D were 9.6 and $3.5 \mathrm{ml}$. Consumption of the nonreinforced flavor Y showed no such reduction; for Group D, the mean level of consumption was $8.8 \mathrm{ml}$ on the first trial and $9.4 \mathrm{ml}$ on the second. Corresponding data for Group D were 9.1 and $9.3 \mathrm{ml}$. An analysis of variance (ANOVA) performed on these data revealed reliable main effects of stimulus and of trial and a reliable interaction between these factors [smallest $F(1,14)=168.92$ ]. No other main effects or interactions were reliable. (In this and subsequent analyses a significance level of $p<.05$ was adopted.)

The data of central interest are those of the two test trials. An initial ANOVA performed on these data revealed no main effect or interactions involving the test trial factor (smallest $p>.20$ ), so data are presented and analyzed collapsed over this factor. Figure 1 shows the group mean levels of consumption per test trial of the flavors $A$ and B for Groups S and D. It is clear that both groups showed a preference for flavor $B$ over flavor $A$. This preferential rejection of the flavor (A) that had been preexposed in the presence of the conditioned $\mathrm{X}$ stimulus constitutes a demonstration of the standard sensory preconditioning effect (see, e.g., Rescorla \& Cunningham, 1978). More important for our present concerns, Figure 1 also shows that the preference for flavor B over flavor A was less marked in Group D than in Group S; that is, the sensory preconditioning effect appears to have been attenuated by the change of context experienced by subjects in Group D. This impression was confirmed by statistical analysis. An ANOVA with group and stimulus as the factors revealed no main effect of group $[F(1,14)=1.15]$, a main effect of stimulus $[F(1,14)=14.25]$, and an interaction between these factors $[F(1,14)=4.93]$. An analysis of simple main effects revealed the difference in consumption of flavors A and B to be significant for Group $\mathrm{S}[F(1,14)=$ 17.97] but not significant for Group D $[F(1,14)=1.21]$.

The attenuation of sensory preconditioning in Group D is consistent with the suggestion that within-compound 
associations formed during sensory preconditioning are susceptible to contextual modulation in the same way as those formed between a CS and a US in orthodox conditioning. We have suggested that the source of the sensory preconditioning effect is that, following exposure to an $A X$ compound, conditioning with $X$ allows $A$ to evoke the $C R$ by way of the associative chain A-X-US. A reduction in the size of the effect would be expected, then, if $A$ were unable to activate the representation of $A$ (and hence the US) in a context different from that in which the $\mathrm{A}-\mathrm{X}$ association had been formed. This would be a clear instance of context specificity of within-event learning. Other interpretations may be possible, however.

First, although there was little sign of neophobia to the compound flavors when they were first presented during Phase 1 , it is possible that the $\mathrm{LiCl}$ injections administered in Phase 2 might have induced neophobja to flavors $A$ and $B$ when they were encountered in the test (see, e.g., Domjan, 1975). If such poisoning-induced neophobia were particularly strong for Group D, for whom the flavors had never previously been experienced in Context 2 , then the resulting suppression in the overall level of consumption might have acted to obscure the sensory preconditioning effect. There are, however, two reasons to doubt this analysis. First, the overall level of fluid consumption on the test in Group D was not particularly low; indeed, Group D drank rather more of flavor A than did Group S. Second, the analysis rests on the assumption that habituation of neophobia will be context specific; explicit investigations of this matter, however, have failed to detect dishabituation with a change of context (e.g., Domjan, 1977; Hall, 1991).

Two other possible explanations for the results of Experiment 1 are less readily dismissed. First, it is possible that during Phase 2 conditioning of flavor $\mathrm{X}$, the context itself also entered into an association with the US (see, e.g., Best, Brown, \& Sowell, 1984; Symonds \& Hall, 1997). Thus, for Group $S$, the test took place in a context that was potentially excitatory, whereas Group D was tested in a neutral context. If the presence of an excitatory background enhances the CR governed by a mildly excitatory test flavor (such as flavor A will be), then the performance of Group S can be explained without supposing that contextual cues directly modulate the effectiveness of the A-X association. A further possibility is that $A$ was indeed perfectly effective in evoking the representation of $X$ in Group D, but that X was incapable of fully activating the US representation. The change of context occurred after conditioning to flavor $\mathrm{X}$, and context specificity of flavor aversion learning is an established phenomenon (Bonardi et al., 1990). Our results might reduce, therefore, to a further demonstration of this effect. Experiment 2 was designed to address these issues.

\section{EXPERIMENT 2}

In this experiment (the design of which is summarized in the lower part of Table 1), all rats received exposure to the compound $\mathrm{AX}$ in one context (Context 1 ) and to the compound BY in a second context (Context 2). In Phase 2, the rats received conditioning trials with both $\mathrm{X}$ and $\mathrm{Y}$ in Context 1. The final two-bottle test of flavors $A$ and $B$ also occurred in Context 1 . Both of these flavors might be expected to produce conditioned responding, because their partners, $X$ and $Y$, had both been conditioned in the preceding phase. If, however, sensory preconditioning is to any extent contextually dependent, less conditioned responding should be seen to element $B$ than to element $A$, because element $B$ was paired with its associate, $Y$, in a context different from that used for the test. Note that with this within-subjects design, in which all subjects are tested in Context 1 , the excitatory strength of the contextual cues cannot contribute to any difference observed in responding to $A$ and $B$. And because the elements $X$ and $Y$ are both conditioned in Context 1 , a preference for $A$ over B cannot be attributed to a failure of the Y-US association to transfer to the test phase.

A possible disadvantage of this design arises when we consider the fact that latent inhibition tends to be attenuated by a change of context (see, e.g., Hall \& Channell, 1986). Phase 2 conditioning to $Y$, which occurred in a different context from that in which $Y$ was preexposed, might thus be expected to proceed more readily than conditioning to $\mathrm{X}$. For this reason the aversion shown on test to $B$ (Y's associate) might be greater than that shown to A (X's associate). It should be noted, however, that the result anticipated on the basis of the context specificity of sensory preconditioning is that the aversion will be greater to A than to B. The context-specificity of latent inhibition might act to obscure such an effect, should one be found, but could not be responsible for a preference for $\mathrm{B}$ over $\mathrm{A}$.

\section{Method}

The subjects were 16 male hooded Lister rats with a mean weight of $448 \mathrm{~g}$ (range: $380-500 \mathrm{~g}$ ). They had a training history identical to that of the subjects employed in Experiment 1 and were thus naive with respect to the current stimuli and procedures. The apparatus and experimental contexts were those used in Experiment 1. Details of this experiment which were the same as those of Experiment 1 have been omitted.

All subjects received 8 days of Phase 1 training in which they were given access on aiternate days to the fiavor compounds $\mathrm{AX}$ in Context 1 and $B Y$ in Context 2. For all subjects, the first trial in the sequence occurred in Context 1 . During Phase 2 , animals received one $\mathrm{LiCl}$ - reinforced trial with $\mathrm{X}$ and one with $\mathrm{Y}$. Each trial was followed by a recovery day. For half the animals, the first reinforced trial was with $\mathrm{X}$; for the remainder, it was with $\mathrm{Y}$. Conditioning occurred in Context 1 for all rats. Finally, rats were given access to elements A and B in a single two-bottle choice test in Context 1 . All training was given in the morning at $1100 \mathrm{~h}$ and $30 \mathrm{~min}$ of free access to water were given in the afternoon at $1700 \mathrm{~h}$.

\section{Results and Discussion}

During Phase 1, the subjects drank all or very nearly all of the fluid offered. On the Phase 2 conditioning trials, flavors $X$ and $Y$ were drunk with equal readiness, the group means being $5.8 \mathrm{ml}$ for $\mathrm{X}$ and $5.5 \mathrm{ml}$ for $\mathrm{Y}(F<1)$. 


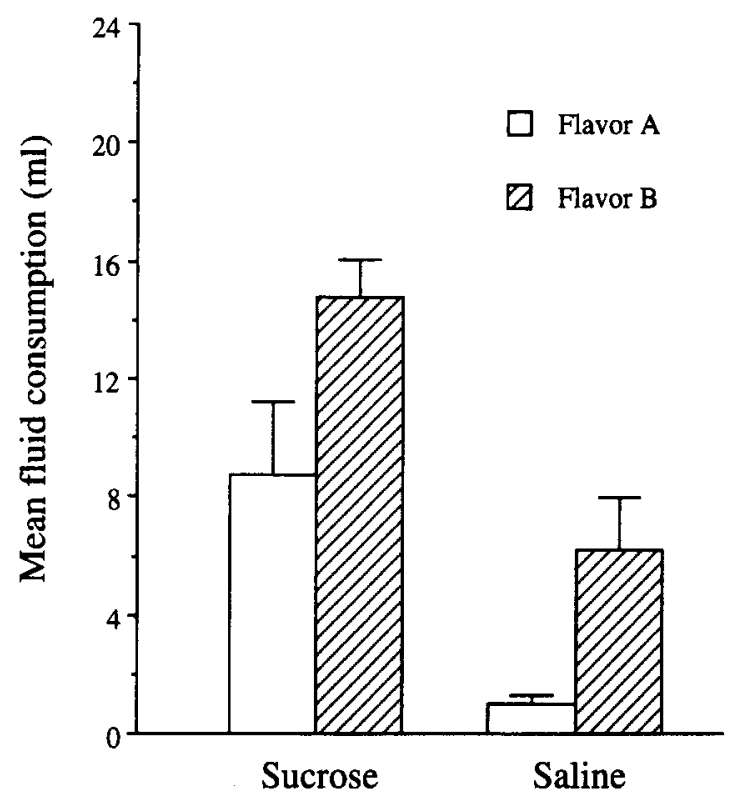

Figure 2. Experiment 2. Group mean consumption (in milliliters) of flavors $A$ and $B$ on the test session. A had been preexposed in compound with a flavor $(X)$ that was subsequently reinforced in the context that was used for both preexposure and the test. $B$ had been preexposed in compound with $Y$ in a different context from that used for conditioning $Y$, and for the test. Error bars indicate the standard error of the mean.

The data of primary interest, those from the two-bottle test with flavors A and B, are summarized in Figure 2. For some reason (no such effect was seen in Experiment 1, in which the same flavors and concentrations were used), there was a marked preference for sucrose over saline. Accordingly, the mean levels of consumption of sucrose and of saline are presented separately in the figure and were subjected to separate analyses. Taking first the consumption of sucrose, it can be seen that less was consumed when that flavor served as A than when it served as B $[t(14)=2.16]$. The same is true of the saline consumption: Less was consumed when that flavor served as $A$ than when it served as B $[t(14)=2.95]$.

These results thus confirm and extend those of Experiment 1 . The sensory preconditioning effect is shown to be attenuated by a change in context, which in this case occurred after Phase 1 of training and before the conditioning phase. The use of a design which ensured that all animals received the test phase in the context in which conditioning had occurred allows us to rule out the alternative explanations that were considered for the results of Experiment 1. We conclude that the present results are what would be expected if sensory preconditioning depends on the formation of within-compound associations during Phase 1, and that these associations, like others that have been investigated in standard conditioning procedures, are rendered less effective by a change of context.

\section{GENERAL DISCUSSION}

The sensory preconditioning procedure used in the present experiments confirms that learning of some sort occurs when two stimuli are experienced together in a simultaneous compound. The change in behavior produced by modifying the value of one of the elements of the compound also shows in the response evoked by the other element of the compound. Although in these experiments the compound was constructed artificially from separable elements, the learning processes revealed by the study of such a compound will presumably be at work during nonreinforced exposure to any stimulus, since any stimulus can be regarded as being composed of a set of distinguishable (if not easily separable) elements (see Estes, 1950; McLaren, Kaye, \& Mackintosh, 1989).

Our new finding is that the learning that goes on during compound preexposure shows context specificity. Given the fact that such specificity is a feature of orthodox classically conditioned associations, this outcome is to be expected by any theory that interprets sensory preconditioning in terms of the formation of associations between the elements during compound preexposure. The associative account of sensory preconditioning assumes that the critical consequence of exposure to the $\mathrm{AX}$ compound is that it allows the formation of an association or associations between $A$ and $X$. This could generate the effect observed in two ways (see, e.g., Honey \& Hall, 1991; Rescorla \& Freberg, 1978). First, the formation of an $\mathrm{A} \rightarrow \mathrm{X}$ association means that $\mathrm{A}$ would be able to activate a representation of $X$ during the test phase, allowing the $\mathrm{CR}$ to be elicited via the associative chain $\mathrm{A} \rightarrow \mathrm{X} \rightarrow \mathrm{US}$. This standard account of sensory preconditioning applies equally readily to procedures in which $\mathrm{A}$ and $\mathrm{X}$ are presented serially in the first phase of training as it does to the procedure used here. But the use of a simultaneous compound in preexposure allows the possibility that another associative mechanism might operate. The formation of an $\mathrm{X} \rightarrow \mathrm{A}$ association makes it possible that, during conditioning with $X$, a representation of $A$ might be activated which could then form a direct link with the US. A would then be able to evoke the CR on test (see Holland, 1981; Rescorla \& Freberg, 1978; Ward-Robinson \& Hall, 1996).

Our results do not allow us to decide which of these associative mechanisms might be of greater importance in determining the basic sensory preconditioning effectboth would be rendered less potent by a failure to retrieve the association between $\mathrm{A}$ and $\mathrm{X}$. Some evidence relevant to this issue comes from a study by Westbrook, Duffield, Good, Halligan, and Seth (1995, Experiment 5), who failed to detect context sensitivity of within-event learning. Rats were given a solution of almond and salt during the preexposure phase and were tested for consumption of the almond flavor in either the same or a different context. There was no phase of conditioning to 
saline - instead the value of the saline was modified by the induction of a salt need. This procedure was effective in enhancing the consumption of almond, evidence for within-event learning during preexposure. However, this enhancement was evident in both test contexts. This experiment has much in common with those reported here, and it is possible that the discrepancy in the results derives from the major procedural difference between them - the absence of a separate conditioning phase in Westbrook et al.'s study. Recall that of the two suggested associative mechanisms for sensory preconditioning, one operated during conditioning and one at test. Thus, the sensory preconditioning shown by Westbrook et al.'s experiment can only have been controlled by the test mechanism, which must be assumed not to have shown context sensitivity. A possible implication of this conclusion is that the effects seen in the present work are entirely due to the context dependence of the conditioning phase mechanism. It is important to emphasize, however, that many experimenters have been unable to detect any contextual sensitivity of excitatory conditioning (e.g., Bouton \& King, 1983; Bouton \& Peck, 1989; Kaye \& Mackintosh, 1990; Lovibond et al., 1984), and so we must be cautious about this suggestion.

As with all experiments showing context specificity of learning, it is necessary to acknowledge the role of generalization decrement as a possible source of the effect. For example, one might imagine that rats' exploration of a pair of experimental contexts might differ. This raises the possibility that the rats' reception of the CS may be different in the two contexts-something that could act to reduce the size of the $\mathrm{CR}$ when the context is changed between conditioning and testing. However, casual observation during the present experiments suggests that this is unlikely: Upon placement in the context, rats tended to quickly locate the drinking spout and explore the context only after consumption of the solution. It is, however, possible that the contexts modified reception of the flavor cues more subtly. Perhaps Contexts 1 and 2 had discriminably different odors that interacted with the flavor of the stimuli. In Experiment 2, for example, the two contexts may have altered the compound flavors such that they were experienced as AXp and BYq (see, e.g., Wagner \& Rescorla, 1972). On test, therefore, A may again generate the cue $p$, which could effectively retrieve the $\mathrm{X}$-US relationship. But, because $\mathrm{BY}$ is presented in a different context, the cue q would not be generated and, therefore, could not contribute to the generation of conditioned responding. This interpretation requires some qualification however: Contexts 1 and 2 were characterized only by temporal, visual, and tactile features. And, although the contexts may have had some faint odor, it is noteworthy that experiments providing direct evidence for such processes have used markedly more salient stimuli (e.g., Rescorla, 1973).

Although some details remain to be resolved, it remains generally true that the effects obtained in our experiments can be accommodated by theories that try to ex- plain the phenomena of within-event learning in associative terms. But we also need to consider the implications of our results for alternative, nonassociative interpretations such as those of Rescorla (1983) and Rescorla and Durlach (1981). These authors consider the possibility that sensory preconditioning can usefully be regarded as an instance of generalization between the representation of a compound and its component parts. They suggest that presentation of a compound stimulus, AX, might result not (or not only) in its being analyzed or perceived in terms of its individual elements, but as constituting a unitary stimulus (see also James, 1890). If this unitary representation is perceived as being rather similar to the elements, it could mediate generalization between $\mathrm{A}$ and $X$. Strength acquired by A during conditioning would generalize to $\mathrm{AX}$, and the similarity of $\mathrm{AX}$ to $\mathrm{X}$ could then constitute a source of generalized responding when the latter is presented during the test phase.

There is some empirical evidence to support this notion that compound preexposure allows the formation of a unitary representation. In particular, presentation of the elements outside the compound has been found to undermine the sensory preconditioning effect (e.g., Bolhuis \& Honey, 1994; Rescorla, 1983; Rescorla \& Freberg, 1978; Westbrook et al., 1995), perhaps because it promotes a tendency for the subjects to dissociate the otherwise unitary compound stimulus into its components. It might be possible to provide a partial explanation of the results of the present experiment by invoking such a process. If it is assumed that presentation of the $\mathrm{A}$ and $\mathrm{X}$ elements outside the AX compound (i.e., during the conditioning and test phase) in a context different from that used for preexposure is especially effective in enhancing their distinctiveness (see, e.g., Hall, 1991), then the outcome might be a reduction in the generalization presumed to be responsible for the sensory preconditioning effect. It should be pointed out immediately, however, that the assumptions required by this argument are no more than speculation, making the associative interpretation the more parsimonious alternative at this stage.

A related, but better specified, theory has been discussed by Pearce (e.g., 1994). However, despite its apparent similarity to the unitary stimulus account described above, this theory does not easily anticipate the basic sensory preconditioning effect of Experiment 1 . According to the model, conditioned responding on test generalizes from flavor $\mathrm{X}$ to flavors $\mathrm{A}$ and $\mathrm{B}$. This generalization will be proportional to the similarity of $\mathrm{X}$ to $A$ and $B$, and because $A$ and $B$ are counterbalanced (and therefore equally similar to X), Pearce's theory does not predict any difference in their consumption. However, as Rescorla and Durlach (1981) have suggested, the Phase 1 treatment of the experiment could allow the formation of a unitary representation, or configural unit, of the AX compound flavor. Now, if one assumes that this unitary representation could mediate generalization, it would be possible for Pearce's theory to anticipate sensory preconditioning: Associative strength could generalize from 
$\mathrm{X}$ to $\mathrm{AX}$, and from $\mathrm{AX}$ to $\mathrm{A}$, to produce the observed difference in consumption of flavors A and B on test. But, in order to accommodate phenomena such as blocking, Pearce's theory explicitly demands that no such mediation occur (e.g., Pearce, 1987, p. 67). It is important to note that the demonstration of sensory preconditioning is not in itself sufficient to challenge Pearce's model: That theory also makes standard assumptions about associative learning and may therefore anticipate that sensory preconditioning will be governed by the associative mechanisms discussed above.

If an associative interpretation of sensory preconditioning is accepted, our findings may be summarized as showing that within-stimulus associations are context specific. At this stage, it is worth considering the ways in which our findings might bear on other phenomena that have been shown to result from stimulus preexposure. First, it is well documented that nonreinforced preexposure to a CS will cause a retardation of conditioning to that stimulus - the latent inhibition effect. It is also well established that latent inhibition is attenuated if the target stimulus is conditioned in a context different from that in which preexposure took place (e.g., Hall \& Channell, 1986; Lovibond et al., 1984). This finding, taken together with those of the present study, accords with at least one account of the latent inhibition effect. McLaren et al. (1989) attribute latent inhibition (in part) to a loss of associability consequent to the formation of associations among the constituent elements of the target stimulus during the preexposure phase. This theory can thus comfortably predict the context dependency of latent inhibition by accepting that the change of context reduces the effectiveness of the within-stimulus links on which latent inhibition is taken to depend.

It has also been shown that preexposure to stimuli will not only produce latent inhibition but result in a perceptual learning effect-that is, enhance the discriminability of the stimuli or reduce generalization between them (see Hall, 1991, for a review). In the light of our present findings, it is of interest that the only tightly specified account of the perceptual learning effect is one that invokes the formation of within-stimulus links among the elements of the target stimuli (McLaren et al., 1989). It follows, therefore, that the perceptual learning effect, like latent inhibition, should also show context dependency. The evidence on this matter is decidedly mixed. Although it has sometimes been found that perceptual learning is attenuated by a change of context (Trobalon, Chamizo, \& Mackintosh, 1992), other experiments have demonstrated that the effect can survive (e.g., Gibson \& Walk, 1956), or even be enhanced by (Channell \& Hall, 1981; Hall \& Channell, 1983), a context change. For the latter cases at least, it seems necessary to assume that the processes that produce the perceptual learning effect do not depend on within-stimulus associations of the sort postulated by McLaren et al. (1989). Our results do not, however, provide any indication as to what these processes might be.

\section{REFERENCES}

Best, M. R., Brown, E. R., \& Sowell, M. K. (1984). Taste-mediated potentiation of noningestional stimuli in rats. Learning \& Motivation, 15, 244-258.

Bolnuis, J. J., \& Honey, R. C. (1994). Within-event learning during filial imprinting. Journal of Experimental Psychology: Animal Behavior Processes, 20, 240-248.

Bonard, C., Honey, R. C., \& Hall, G. (1990). Context specificity of conditioning in flavor-aversion learning: Extinction and blocking tests. Animal Learning \& Behavior, 18, 229-237.

Bouton, M. E., \& King, D. A. (1983). Contextual control of the extinction of conditioned fear: Tests for the associative value of the context. Journal of Experimental Psychology: Animal Behavior Processes, 9, 248-265.

Bouton, M. E., \& PeCK, C. A. (1989). Context effects on conditioning, extinction, and reinstatement in an appetitive conditioning preparation. Animal Learning \& Behavior, 17, 188-198.

Brogden, W. J. (1939). Sensory pre-conditioning. Journal of Experimental Psychology, 25, 323-332.

Channell, S., \& Hall, G. (1981). Facilitation and retardation of discrimination learning after exposure to the stimuli. Journal of Experimental Psychology: Animal Behavior Processes, 7, 437-446.

Domuan, M. (1975). Poison-induced neophobia in rats: Role of stimulus generalization of conditioned taste aversions. Animal Learning \& Behavior, 3, 205-211.

Domjan, M. (1977). Attenuation and enhancement of neophobia for edible substances. In L. M. Barker, M. R. Best, \& M. Domjan (Eds.), Learning mechanisms in food selection (pp. 151-179). Waco, TX: Baylor University Press.

EsTES, W. K. (1950). Towards a statistical theory of learning. Psychological Review, 57, 94-107.

Gibson, E. J., \& WALK, R. D. (1956). The effect of prolonged exposure to visually presented patterns on learning to discriminate them. Journal of Comparative \& Physiological Psychology, 49, 239-242.

Good, M., \& Honey, R. C. (1991). Conditioning and contextual retrieval in hippocampal rats. Behavioral Neuroscience, 105, 499-509.

HALL, G. (1991). Perceptual and associative learning. Oxford: Oxford University Press, Clarendon Press.

Hall, G., \& Channell, S. (1983). Stimulus exposure and discrimination in rats: A test of a theory for the role of contextual factors. Quarterly Journal of Experimental Psychology, 35B, 135-147.

Hall, G., \& Channell, S. (1986). Context specificity of latent inhibition in taste aversion learning. Quarterly Journal of Experimental Psychology, 38B, 121-139.

HALL, G., \& Honey, R. C. (1989). Contextual effects in conditioning, latent inhibition, and habituation: Associative and retrieval functions of contextual cues. Journal of Experimental Psychology: Animal Behavior Processes, 15, 232-241.

HALl, G., \& Honey, R. C. (1990). Context-specific conditioning in the conditioned-emotional-response procedure. Journal of Experimental Psychology: Animal Behavior Processes, 16, 271-278.

Holland, P. C. (1981). Acquisition of representation-mediated conditioned food aversions. Learning \& Motivation, 12, 1-18.

Honey, R. C., \& Hall, G. (1991). Acquired equivalence and distinctiveness of cues using a sensory-preconditioning procedure. Quarterly Journal of Experimental Psychology, 43B, 121-135.

Honey, R. C., Pye, C., Lightbown, Y., Rey, V., \& Hall, G. (1992). Contextual factors in neophobia and its habituation: The role of absolute and relative novelty. Quarterly Journal of Experimental Psychology, 45B, 327-347.

Honey, R. C., Willis, A., \& Hall, G. (1990). Context specificity in pigeon autoshaping. Learning \& Motivation, 21, 125-136.

JAMES, W. (1890). The principles of psychology. New York: Holt

KAYE, H., \& MACKINTOSH, N. J. (1990). A change of context can enhance 
performance of an aversive but not of an appetitive conditioned response. Quarterly Journal of Experimental Psychology, 42B, 113-134.

Lovibond, P. F., Preston, G. C., \& Mackintosh, N. J. (1984). Context specificity of conditioning and latent inhibition. Journal of Experimental Psychology: Animal Behavior Processes, 10, 360-375.

McLaren, I. P. L., Kaye, H., \& Mackintosh, N. J. (1989). An associative theory of the representation of stimuli: Applications to perceptual learning and latent inhibition. In R. G. M. Morris (Ed.), Parallel distributed processing: Implications for psychology and neurobiology (pp. 102-130). Oxford: Oxford University Press, Clarendon Press.

Pearce, J. M. (1987). A model for stimulus generalization in Pavlovian conditioning. Psychological Review, 94, 61-73.

PEARCE, J. M. (1994). Similarity and discrimination: A selective review and a connectionist model. Psychological Review, 101, 587-607.

ResCoRla, R. A. (1973). Evidence for a "unique stimulus" account of configural conditioning. Journal of Comparative \& Physiological Psychology, 85, 331-338.

Rescorla, R. A. (1981). Simultaneous associations. In P. Harzem \& M. Zeiler (Eds.), Advances in analysis of behavior: Vol. 2. Predictability correlation and contiguity (pp. 47-79). Chichester, U.K.: Wiley.

RESCORLA, R. A. (1983). Effect of separate presentation of the elements on within-compound learning in autoshaping. Animal Learning \& Behavior, 11, 439-446.

Rescorla, R. A., \& CUNNingham, C. L. (1978). Within-compound flavor associations. Journal of Experimental Psychology: Animal Behavior Processes, 4, 267-275.

Rescorla, R. A., \& Durlach, P. J. (1981). Within-event learning in
Pavlovian conditioning. In N. E. Spear \& R. R. Miller (Eds.), Information processing in animals: Memory mechanisms (pp. 81-111). Hillsdale, NJ: Erlbaum.

Rescorla, R. A., \& Freberg, L. (1978). The extinction of withincompound flavor associations. Learning \& Motivation, 4, 411-427.

SWARTZENTRUBER, D., \& Bouton, M. E. (1992). Context sensitivity of conditioned suppression following preexposure to the conditioned stimulus. Animal Learning \& Behavior, 20, 97-103.

Symonds, M., \& Hall, G. (1997). Contextual conditioning with lithium-induced nausea as the US: Evidence from a blocking procedure. Learning \& Motivation, 28, 200-215.

Trobalon, J. B., Chamizo, V. D., \& Mackintosh, N. J. (1992). Role of context in perceptual learning in maze discriminations. Quarterly Journal of Experimental Psychology, 44B, 57-73.

WAGNeR, A. R., \& Rescorla, R. A. (1972). Inhibition in Pavlovian conditioning: Application of a theory. In R. A. Boakes \& M. S. Halliday (Eds.), Inhibition and learning (pp. 301-336). London: Academic Press.

WARD-Robinson, J., \& HALL, G. (1996). Backward sensory preconditioning. Journal of Experimental Psychology: Animal Behavior Processes, 22, 395-404.

Westbrook, R. F., Duffield, T. Q., Good, A. J., Halligan, S., \& SETH, A. K. (1995). Extinction of within-event learning is contextually controlled and subject to renewal. Quarterly Journal of Experimental Psychology, 48B, 357-375.

(Manuscript received August 22, 1997; revision accepted for publication November 20, 1997.) 